\title{
PROSPECT OF INDIGENOUS PLANT EXTRACTS IN TEA PEST MANAGEMENT
}

\author{
M.S.A. Mamun ${ }^{1 *}$ and M. Ahmed ${ }^{2}$ \\ Received 13 September 2011, Revised 1 November 2011, Accepted 25 December 2011, Published online 31 December 2011
}

\begin{abstract}
Tea is a popular beverage made from the leaves of evergreen shrub or tree Camellia sinensis, under the family Theaceae. Tea plant is subjected to the attack of insects, mites, nematodes and some plant pathogenic diseases. Tea production is greatly hindered due to these maladies. About 10-15\% crop loss occurred by these pests per annum. In severe cases, it would be $100 \%$. To combat these problems different groups of pesticides have been used in the tea fields since 1960. As tea is a consumable commodity, the effect of residue of pesticides in made tea is harmful to human health. In this context, biopesticides are being considered as environmentally safe, selective, biodegradable, economical and renewable alternatives for use in IPM programmes. Biopesticides are natural plant products and may be grown by the planters with minimum cost and extracted by indigenous methods. Biopesticides are secondary metabolites, which include alkaloids, terpenoids, phenolics, and minor secondary chemicals. It is estimated that as many as 2121 plant species have been reported to posses' pest control properties. Botanicals like neem, ghora-neem, mahogoni, karanja, adathoda, sweet flag, tobacco, derris, annona, smart weed, bar weed, datura, calotropis, bidens, lantana, chrysanthemum, artemisia, marigold, clerodendrum, wild sunflower and many others may be grown by planters with minimum expense and extracted by indigenous methods. These botanical materials can be used as an alternative to chemical pesticides. These botanical extracts will help in controlling major pests of tea such as Helopeltis, red spider mite, aphids, thrips, jassid, flushworm, termites, nematodes etc. The present note reviews the information of most widely available indigenous plants that may be used for the control of insect pests of tea as a component of IPM.
\end{abstract}

Keywords: Prospect, Biopesticide, Plant Extracts, Tea Pest Management

${ }^{1}$ Entomology Division, Bangladesh Tea Research Institute, Srimangal, Moulvibazar, Bangladesh;

${ }^{2}$ Director in-charge, Bangladesh Tea Research Institute, Srimangal, Moulvibazar, Bangladesh

*Corresponding author's email: shameembtri@ yahoo.com

Reviewed by Duraikannu Vasanthakumar, UPASI Tea Research Institute, Valparai, Tamil Nadu, India

\section{Introduction}

Tea is predominantly an agro-based, exportoriented, evergreen, perennial crop grown as a monoculture on large contiguous areas. Tea plant is subjected to the attack of pests, diseases and weeds. In world tea, 1034 species of arthropods, 82 species of nematodes, 1 algal disease and 350 fungal diseases are associated with tea plants (Chen and Chen, 1989). So far 4 mites, 25 insects, 10 nematodes, 18 fungal and 1 algal diseases and 37 preponderant weed species have been recorded in tea plantation in Bangladesh (Sana, 1989). Crop loss caused by pest attack is reported to be about 10-15\% annually (Ahmed, 2005).

As a long-lived woody perennial and monoculture, tea provides a stable microclimate and a continuous supply of food for rapid build up of phytophagous species that includes insects, mites and eelworms. Each tea growing country has its own distinctive pests, diseases and weeds. Tea mosquito bugs, Red spider mite, Termites, Flushworm, Aphid, Jassid, Thrips and Nematodes are the major pests of tea in Bangladesh (Mamun, 2011a). To combat these problem different groups of pesticides like organochlorine, organophosphate, pyrethroids, carbamates and some unclassified group have been used in the tea fields since 1960. Chemical pesticides have been used for a long time, but have serious drawbacks (Sharaby, 1988), such as direct toxicity to beneficial insects, fishes and human (Goodland et al., 1985), pesticide induced resistance (Georghiou and Taylor, 1977), health hazard (Bhaduri et al., 1989) and increased environmental and social costs (Pimental et al., 1980). Overzealous and 
indiscriminate use of many synthetic pesticides during recent decades in the control of plant pests has resulted in a number of environmental and toxicological problems. Reducing the release of synthetic chemicals into the environment requires that alternative sources of chemicals are developed that can be used safely in the management of plant pests. Looking back into the early records of tea pest control history, natural product e.g. tobacco extract, liquid cowdung, muddy water and lime sulphur were the principal materials for pest control. With no other exception in other tea growing countries, in Bangladesh also chemical control has been a dominating feature in pest control in tea and passed through three generation of pesticides. Besides these three generation of pesticides, a fourth generation is in the process which consists of bio-pesticides like neem or other indigenous plant extracts, Bacillus thuringiensis etc.

As tea is a consumable commodity, the effect of residue of pesticides in made tea is harmful to human health. Heavy reliance on pesticides has not worked well in terms of integrated pest management (IPM) of insect pests. It is essential to find out some eco-friendly alternative methods for tea pest management. In many countries, efforts are being made to minimize the use of harmful insecticides through the use of indigenous plant products, implementation of IPM approaches, use of bio-degradable products (Khattach and Hameed, 1986) and applying insect growth regulators (Metcalf, 1975). In this context, biopesticides are being considered as environmentally safe, selective, biodegradable, economical and renewable alternatives for use in IPM programme (Mamun, 2011c). Plant scientists and agriculturists now devote significant attention to discovery and further development and formulation of novel plant products with antimicrobial activity. Instead, tea entomologists have focused their attention to develop environmentally safe, long-lasting and effective biocontrol methods for the management of insect pests of tea. Interestingly, extracts of certain plants contain alkaloids, tannins, quinones, coumarins, phenolic compounds and phytoalexins, which are known for pesticidal activity. Recently, various plant extracts and plant parts have been reported to have insecticidal properties (Mahmood et al., 1984). Some plant extracts posseses significant oviposition difference or antifeedant or toxic effects on selected tea pests (Hazarika et al., 2008). This article is the first to bring together relevant aspects of the basic and applied sciences of natural pesticides and discussed modern trends in the use of natural products in tea pest management.

\section{Indigenous plant extracts in tea pest management}

Botanical antimicrobials derived from plants are currently recognised as biodegradable, systemic, eco-friendly and non-toxic to mammals and are thus considered safe. Their modes of action against pests are diverse. Natural compounds are well suited to organic food production in industrialised countries and can play greater roles in the protection of food crops in developing countries. Some plant based antimicrobials (e.g. neem products, pyrethroids and essential oils) are already used to manage pest populations on a large scale.

Botanical products are environmentally safe, less hazardous, economic and easily available. Biopesticides are natural plant products that belong to the so called secondary metabolites, which include alkaloids, terpenoids, phenolics, and minor secondary chemicals. Plants are rich source of bioactive organic chemicals. It is estimated that the plants may contain as many as 4000,000 secondary metabolites (Mamun, 2011b). Certain products derived from plant are uses for tea pest control. As many as 2121 plant species have been reported to posses' pest control properties (Jacobson, 1989); 25 of these plants species posses the characteristics required for an ideal botanical insecticide and are therefore more promising for use in organic pest control programmes (Radhakrishnan, 2005). The anti-pest plants documented included, Capsicum frutescens, Tagetes spp, Nicotiana tabacum, Cypressus spp., Tephrosia vogelii, Azadirachta indica, Musa spp, Moringa oleifera, Tithonia diversifolia, Lantana camara, Phytollacca dodecandra, Vernonia amygdalina, Aloe spp., Eucalyptus spp., Cannabis sativa, Cofea species and Carica papaya (MugishaKamatenesi et al., 2008). Botanical pesticides are extracted from various plant parts (leaves, stems, seeds, roots, bulbs, rhizomes, unripe fruits and flower heads etc.) of different plant species. Botanical pesticides are hailed for having a broad spectrum of activity, being easy to process and use, having a short residual activity and for not accumulating in the environment or in fatty tissues of warm blooded animals, (Philip and Robert, 1998). Some plants have been scientifically tested and have been found to have good pesticidal properties. Botanicals like Bonkalmi, Bazna, Bishkatali, Datura, Durba, Eucalyptus, Ghora-neem, Hijal, Karanja, Mahogoni, Marigold, Neem, Nishinda, Pithraj, and many others may be grown by farmers with minimum expense and extracted by indigenous methods (Mamun et al., 2009). These botanical materials can be used as an alternative to chemical pesticides. It will help in controlling major pests of tea such as Helopeltis, Red spider 
mite, Thrips, Flushworm, Termites, Nematodes etc. The following potential indigenous plants may be used as biopesticides for the control of insect pests of tea.

Neem (Azadirachta indica): Neem has emerged as the single most important source of botanical insecticides having a wide control of numerous insects, mites, fungi, nematodes and viral diseases. Neem is a natural source of eco-friendly insecticides, pesticides and agrochemicals (Brahmachari, 2004). Neem products have no ill effects, on humans and animals and have no residual effect on agricultural produced. Azadirachtin, an oxygenated triterpenoid, obtained from the seed kernels of the neem tree, Azadirachta indica is very effective against pink and purple mites and certain leaf folding caterpillars. About 100 proto-limonoids, limonoids, tetranor-triterpenoids, pentanoortripenoids, hexanor-tripenoids and some nonterpenoids have been isolated from various parts of neem tree and still more are being isolated. These compounds and neem extracts exhibits almost every type of biological activity conceivable against a wide range of insects. More than 400 species of insects have been reported to be affected by neem compounds (Schmutterer and Singh, 1995). Neem exhibits antifungal activity also. Neem leaves and seeds contain azadirachtin, miliantriol etc. having insecticidal properties. These constituents are more in seeds than in other parts of the plant. Now neem is being used in different formulations such as neem seed kernels extracts (NSKE), neem decoction, neem oil, neem cake etc. for the control of pests. Aqueous plant extract of A. indica exhibited significant effect on feeding to tea mosquito bug (Sarmah and Bhola, 2008). So, neem can be used for the control of Helopeltis, Red spider mites, Thrips, Flushworm, Scales, Termites, Looper caterpillar and Nematodes etc. About $25 \mathrm{~kg}$ neem seeds are required to spray in one hectare area of tea plantation. The spray solution now at $5 \%$ concentration can be used as a spray to repel the insect pests if any (Mamun, 2008). To spread the spray solution uniformly over the leaves, an emulsifier has to be used. The locally available and cheapest emulsifier is the soap powder. About 50 to $60 \mathrm{gm}$ of the soap powder which will be about 15 to 20 teaspoons has to be thoroughly mixed in the knapsack sprayer. This solution can also be used for a prophylactic application before the onset of pest attack. The extract should be used within a day after making in to a formulation to prevent degradation of the active ingredients. For enhancing the effectiveness, the spray should wet the whole plant. Even the lower side of the leaves has to be smeared with the spray as many insects and mites lay egg on the ventral side of the leaves. The extract should be used at least 2-3 times at an interval of 10 to 15 days. Neem cake can be used @ $50 \mathrm{~g}$ per pit before planting seedlings of tea for controlling nematodes. Application of neemcake @ 2kg/ bush was found to be effective for the plants suffering from the attack of root knot nematodes, Meloidogyne brevicauda (Mamun and Iyengar, 2010).

Ghora-neem (Melia azedarach): The plant is also useful for tea pest management. Melia azedarach is reported to be the potential source of azadirachtin and salanin that have high insecticidal property. Several workers have reported the relative efficacy of oil cakes from Melia azedarach in reducing root knot nematode infestation in cowpeas (Radhakrishnan, 2005). The seed contains terpenes (mono and sesqueterpenes) and lactones act as nematicides. So, it could be incorporated in biopesticides for the control of nematodes in tea. The seed extract shows some antifeedant activity against Helopeltis.

Mahogoni (Swietenia mahagoni): The seeds of the Mahogoni plant are very toxic to the insect pests and diseases. So, the seed kernels should be crushed and mixed with water to prepare the extracts. The extracts are very effective for the control of Helopeltis, Red spider mites in tea (Mamun and Ahmed, 2011).

Karanja (Pongamia pinnata): The seeds of karanja are also lethal to the insect pests. The seed extracts of this plant will be very effective to control Helopeltis, Red spider mites and other minor insects of tea. The aqueous seed extract at $10 \%$ of karanja reduce the infestation of Helopeltis (43.33\%) in tea (Deka et al., 2000). Oilcakes of P. pinnata reduce the infestation of root knot nematodes.

Exodus (Sophora flavescens): A formulation called Exodus containing extracts of a leguminous plant Sophora flavescens has been proved very effective against red spider mites in tea (Muarleedharan, 2005).

Adathoda (Adathoda vasica): The plants have some ovicidal and antifeedant properties against Helopeltis (Gurusubramanian et al., 2008). One $\mathrm{kg}$ of fresh leaves are finely pounded, mixed with six litres of water and allowed to soak for one day. Then the liquid is filtered and a suitable sticker such as soap is added. Applications are best done in the evening time after sunset. This will effectively control mites in tea. This should be applied daily for three consecutive days. The mode of action is antifeedant, insecticidal and acaricidal.

Sweet flag (Acorus calamus): Rhizomes of this plant contain calamus, which has insecticidal properties. Saponins and tannins are the main active principles. Pest control formulations are 
obtained by drying and powdering the rhizomes and making an aqueous extracts. It reduces the infestation of red spider mites (60-88\%) and kills eggs (33-70\%) of the red spider mite in tea (Gurusubramanian et al., 2008).

Tobacco (Nicotiana tabacum): Nicotine was known since long as the poisonous material of tobacco. It is a quick acting insecticide. Nicotine is an alkaloid and it disappears quickly after application, hence it is used as nicotine sulphate for insect control. Nicotine sulphate is available in $40 \%$ liquid form. It can be diluted with water and mixed with soap and spray on plants. For preparing the tobacco solutions, $400 \mathrm{~g}$ small pieces tobacco are to be cut and soaked in four litre of water for one day. Collect the clean liquid and add soft soap @ 1ml per liter. This concentrated decoction may be diluted with water and used for spraying against thrips, scales, aphids, looper caterpillars etc.

Rotenone (Derris elliptica): The roots of Derris elliptica a leguminous plant containing $4-11 \%$ rotenone can be used by drying and powdering or by mixing with water. The spray liquid should contain $0.002 \%$ to $0.004 \%$ active ingredient. It is useful against sucking pests, caterpillars and some beetles. It acts as a contact and stomach poison. One hectare of Derris yields about 1.5 litres of roots with $5 \%$ rotenone content, enough active ingredients to treat 500 to 700 ha of tea plantation.

Annona (Annona squamosa): The leaves and seeds of this plant contain lanolin and anonaine having insecticidal properties. The seeds are to be dried, powdered and made into a solution by mixing with water or alcohol for application. It is useful against stem borer, sucking pests, scale insects etc. The aqueous leaf extract of annona has antifeedant activity (66-82\%) against Helopeltis (Gurusubramanian et al., 2008).

Smart weed (Polygonum hydropiper): Leaves and succulent stems of the plant collected, dried, powdered and soaked for 24 hours for extract preparation. $10 \%$ concentrations of aqueous extract of Polygonum hydropiper reduce $60-80 \%$ red spider mite with antifeedant and ovicidal properties (Gurusubramanian et al., 2008). It also reduces Helopeltis to a desirable level.

Drumstick (Moringa oleifera): Drumstick is also a valuable bio-pesticidal plant. Drumstick seeds can be powdered and mixed with stored pulses to repel the beetles and weevils attacking the grains. Also an aqueous extract of the tree's bark is a very powerful repellent.

Albizzia (Albizzia procera): The crude extracts of the seeds of A. procera are very effective against coleopteran insects like beetles and weevils.
Bidens (Bidens pilosa): One tea cup of mature seeds is poured into a container with water and boiled for 10 minutes. After cooling down, one litre of water and small piece of soap is added. The whole plants also be pounded and soaked into two litres of water overnight. The solution may be added with small pieces of soap and sprayed. The solution acts as insecticide for the control of aphids, cutworms and termites in tea.

Bur weed (Xanthium strumarium): Xanthium is a weed having insecticidal and miticidal properties. It has good repellent (84-100\%), ovicidal (47-60\%), antifeedant (27-63\%) against Helopeltis (Sarmah and Bhola, 2008). 5-10\% concentrations of aqueous extract of this plant also reduce the red spider mites (60-80\%) in tea (Sarmah et al., 2009). It also has good ovicidal activity (44-87\%) of red spider mite (Gurusubramanian et al., 2008).

Datura (Datura metel): Datura is one of the toxic plants and can be used as insecticide for the control of Tea mosquito bug, thrips, jassids, aphids etc (Mamun and Ahmed, 2011). 500g of leaves and $500 \mathrm{~g}$ of pods of Datura plants are powdered and soaked in 15 litres of water for 24 hours.

Calotropis (Calotropis gigantea): The plant extracts is very effective against soil pest like termites (Radhakrishnan, 2005). Ten kg plant materials is soaked in water for at least 24 hours, and then filtered. This liquid is poured on termite infested soil. This spray effectively controls the pests within three days.

Castor bean (Ricinus communis): Oilcakes of Ricinus communis is known to have nematicidal properties (Radhakrishnan, 2005). 500g of shelled seeds or $750 \mathrm{~g}$ of unshelled seeds of castor can be crushed. The crushed seeds should be heated in two litres of water for 10 minutes. A bit of soap and two table spoon of kerosene is added. Then the solution is filtered and then 10 more litre of water is added.

Coriander (Coriandrum sativum): $200 \mathrm{~g}$ of crushed seeds are boiled for 10 minutes in one litre of water, filtered, and diluted @ 1:2 with hot water. This will act as a repellent against spider mites in tea (Radhakrishnan, 2005).

Lantana (Lantana camara): The lantana plants containing the flavanoids, triterpenoids and alkaloids such as lantanine are the substance having insecticidal action. Cut $5 \mathrm{~kg}$ of lantana leaves, flowers and fruits into small pieces and partially crush to control root grubs and termites. The leaves and flowers after drying can be extracted with water and used to control many in insects including Helopeltis, aphids (Mamun and Ahmed, 2011). The leaf extract of the plant has excellent acaricidal activity (23- 
95\%) against red spider mite in tea (Gurusubramanian et al., 2008).

Chrysanthemum

(Chrysanthemum

cinerariafolium): It is extracted from the dried flowers of Chrysanthemum. Pyrethrum or natural pyrethroid is a mixture of six different substances. The main active principle is the alkaloid stachydrine. It has the ability to paralyse the pests on contact. Pyrethrum can be effectively used to control sucking pests like Tea mosquito bugs, thrips, aphids, scale insects etc.

Artemisia (Artemisia vulgaris): The plant has excellent antifeedant properties (60-78\%) (Gurusubramanian et al., 2008). Collect Artemisia vulgaris plant before flowering and cut the leaves and stems into small pieces. Take one $\mathrm{kg}$ of cut leaves and stems in a bucket, pour 10 litres of water and keep for 16-24 hours. Then filtered the liquid and sprayed against common insect pests of tea. $10 \%$ concentration of aqueous extract of Artemisia vulgaris reduces the red spider mites in tea.

Aegle (Aegle marmelos): Take 20-25 fruits of Aegle marmelos and boil in 10 litres of water to take the extracts. Then add $1 \mathrm{~kg}$ of turmeric powder and keep it for 12 hours. From the extract, take 1 litre of solution dilute with 10 litres of water and spray over the entire plants to control thrips.

Marigold (Tagetes erecta): Two kg of marigold flowers may be crushed and made into a paste by adding 5-10 litres of water. Then add 5 litres of water and mix the paste. This solution may be mixed with 200 litres of water and sprayed on the plants.

Clerodendrum (Clerodendrum inerme): Clerodendron inerme Linn. is the common name of Ghetu, a common herb of verbenaceae family. The plant also possesses repellent properties. Clerodendrum the most important weed species surrounding tea plantation having both insecticidal and miticidal values. The aqueous extracts at $10 \%$ of Clerodendrum reduce the infestation of Helopeltis in percent of 49.45 (Deka, et al., 2000). Aqueous extract of Clerodendrum inerme gave excellent result in reducing red spider mite (23-100\%) populations as well as Helopeltis (32-60\%) in tea (Gurusubramanian et al., 2008) .

Wild sunflower (Helianthus sp.): 2-10\% concentrations of the aqueous extract of Helianthus sp. reduce the red spider mites (60$100 \%$ ) within three days. To prepare the solution, boil $2 \mathrm{~kg}$ of leaves of Helianthus in 10 litres of water. Dilute one litre of this solution in 10 litres of water.
Besides, the herbal mixture of certain plant is very effective against all kinds of insects, mites, diseases in sustainable tea pest management. The mixture can be made by the following simple procedure. About $500 \mathrm{~g}$ of dried tobacco leaves, one $\mathrm{kg}$ of neem seed kernel, $500 \mathrm{~g}$ lime powder, $500 \mathrm{~g}$ Datura leaves and 500g pods and seeds of olender (Nerium oleander) are powdered and mixed together, then soaked in 15 litres of water for 15 days. On alternate days, the mixture needs to be stirred with stick. After 15 days 1 litre of the filtrate is mixed in 15 litres of water and sprayed on the crop. It is enough for 2.5 ha and is meant to keep away all kinds of pests.

\section{General procedure of indigenous plant extracts}

\section{Collection and processing of plant materials}

Fresh leaves and seeds of indigenous plants are collected from the surrounding of tea plantation areas. After bringing them to the laboratory, they are washed in running water. Firstly the plant materials are kept in shade for air-drying and then they are dried in the oven at $60^{\circ} \mathrm{C}$ to gain constant weight.

\section{Preparation of plant dust}

Dusts are prepared by pulverizing the dried leaves and seeds with the help of a grinder. Then the dusts are passed through a 25-mesh diameter sieve to obtain fine and uniform dust. The dust is preserved in airtight condition in polythene bags till their use in extract preparation.

\section{Preparation of plant extracts}

The prepared leaf and seed dusts are used for preparation of plant extract. Ten gram of each category dust are taken in a $500 \mathrm{ml}$ beaker and separately mixed with $100 \mathrm{ml}$ of different solvents (acetone, methanol and distilled water). Then the mixture is stirred for 30 minutes by a magnetic stirrer (at $6000 \mathrm{rpm}$ ) and left to stand for next 24 hours. The mixture is then filtered through a fine cloth and again through filter paper (Whatman No.1). The filtered materials are taken into a round bottom flask and then condensed by evaporation of solvent in a water bath at $80^{\circ} \mathrm{C}, 55^{\circ} \mathrm{C}$ and $45^{\circ} \mathrm{C}$ temperature for water, methanol and acetone extracts, respectively. Evaporation is done to make the volume $10 \mathrm{ml}$. Stock solutions of plant extracts are prepared separately by diluting the condensed extracts with respective solvents (acetone, methanol and distilled water). Different concentrations as desired such as 5.0, 7.5, 10.0 and $12.5 \%$ etc. of each category of plant extract are prepared by dissolving the stock solutions in the respective solvent prior to use of them. 


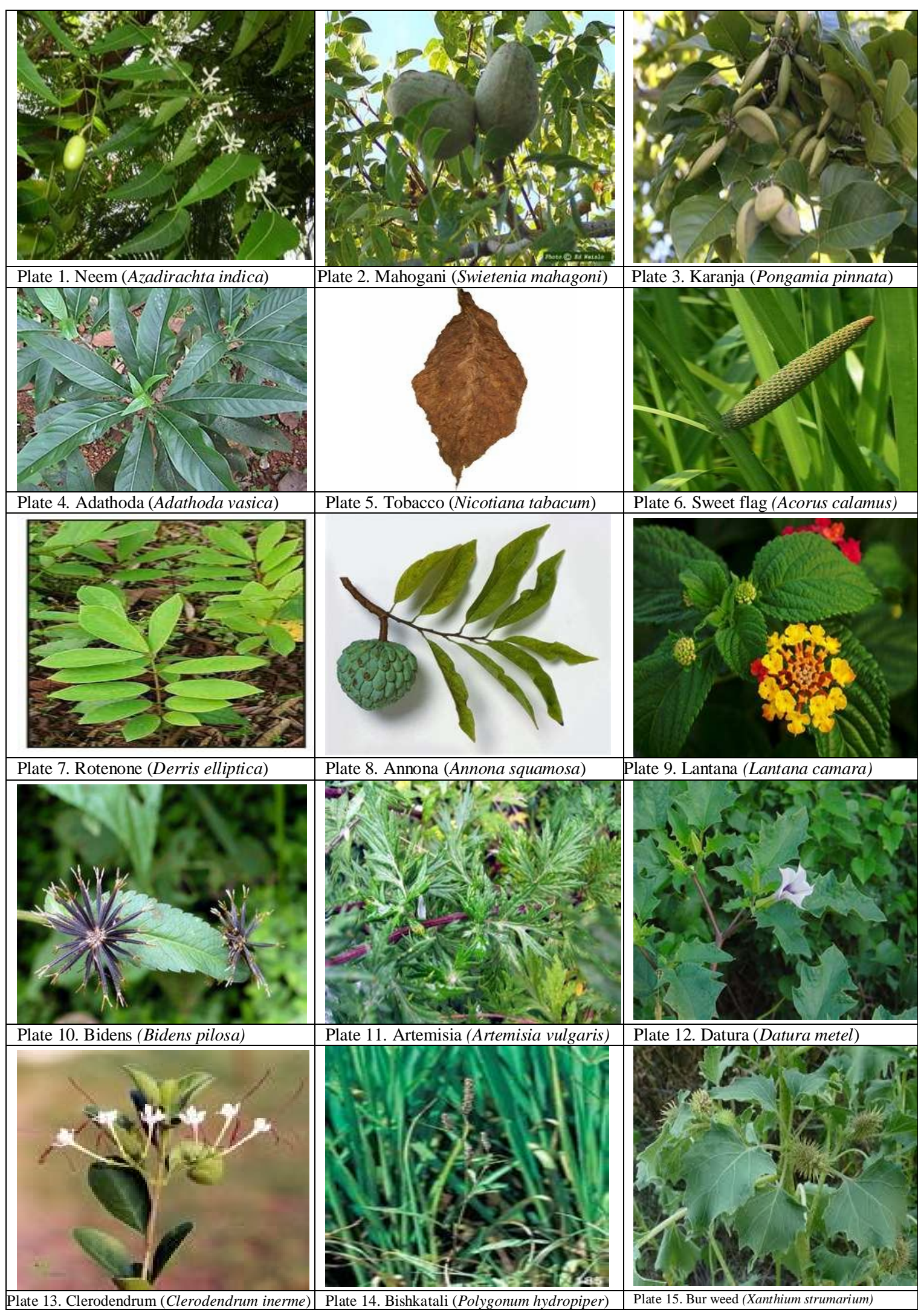

Fig.1. Some potential plants useful in tea pest management 
The simple SOP for the preparation of indigenous plant extracts in general for tea pest management developed by Mamun (2011d) is given below.

\section{Preparation of aqueous plant extracts}

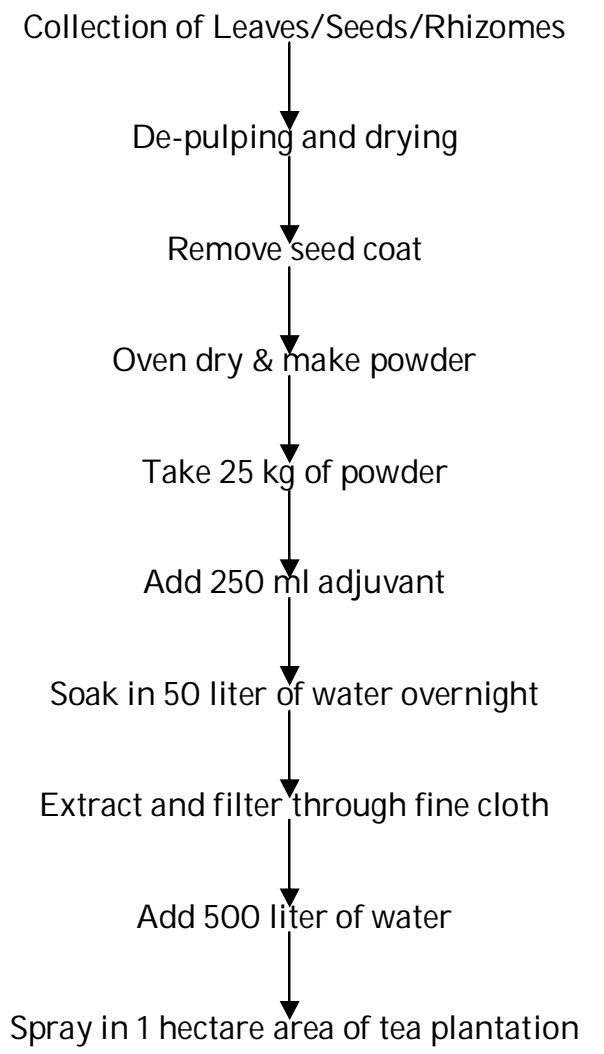

\section{Conclusion}

Tea is an important cash crop as well as exportable commodity. For sustainable tea cultivation, integrated pest management system is the vital component. Planters may use botanical pesticides to perceive to be as effective as the synthetic counterparts. It was also noted that the subsistence planters preferred using botanical pesticides rather than conventional ones mainly because of cost and availability. Traditional pest control methods, especially the use of indigenous pesticide plants if improved, offer a safer, low cost and more dependable method of field crops protection. However, it should not be assumed that because the botanical pesticides are naturally derived that they are safe to use and can be consumed by humans. It intends to carry out a biosafety assessments of the pesticide plants used in order to establish their mammalian and environmental safety. The plants that will be found to have proven effectiveness and safety will be studied further to find out how best they can be used to protect the environment from the increasing degradation. Then, issues of propagation and cultivation as on-farm crop for pest control as well as conservation will be looked at closely in order to enhance crop productivity and food security. The use of plant extracts should be incorporated in the IPM programme in tea. The indigenous plants are available surrounding the tea estates as well as throughout the country. Tea planters may use these plants for the management of pests of tea. It will help for producing pesticide free tea. This will be very helpful in minimizing the undesirable side effects of synthetic pesticides and ultimately environmental pollution will be minimized.

\section{References}

Ahmed, M. 2005. Tea Pest Management. Evergreen Printing and Packaging. Dhaka. p. 118.

Bhaduri, N., Gupta, D.P. and Ram, S. 1989. Effect of vegetable oils on the ovipositional behaviour of Callosobruchus chinensis Fab. pp. 81-84. In: Proc. 2nd Int. Symp. on Bruchids and Legumes (ISBL-2). Okayama, Japan.

Brahmachari, G. 2004. Neem-a omnipotent plant. A retrospection. Chem. Biochem., 5: 408-421.

Chen, Z.M. and Chen, X.F. 1989. An analysis of world tea pest fauna. J. Tea Sci., 9: 13-22.

Deka, M.K., Singh, K. and Handique, R. 2000. Field efficacy of different plant extracts in controlling tea mosquito bug, Helopeltis theivora Waterh. J. Appl. Zool. Res., 11(1): 25-28.

Georghiou, G.P. and Taylor, C.E. 1977. Pesticide resistance as an evolutionary phenomenon. In: Proc. 14th Int. Cong. Entomol. 759 p.

Goodland, R., Watson, C. and Ledec, G. 1985. Biocides bring poisoning and pollution to $3^{\text {rd }}$ world. The Bangladesh Observer, $16^{\text {th }}$ and 17th January, 1995. p. 3.

Gurusubramanian, G., Rahaman, A., Samrah, M., Roy, S. and Bora, S. 2008. Pesticide usage pattern in tea ecosystem, their retrospect and alternative measures. J. Environ. Biol., 29(6): 813-826.

Hazarika, L.K., Barua, N.C., Kalita, S. and Gogoi, N. 2008. In search of green pesticides for tea pest management: Phlogocanthus thyrsiflorus experience. In Recent Trends in Insect Pest Management, ed. S. Ignacimuthu, S. Jayraj. pp. 79-90. New Delhi, Elite Publication, $277 \mathrm{p}$.

Jacobson, M. 1989. Botanical pesticides. Past, present and future. Insecticide of Plant Origin (Eds. J.T. Arnason, B.J.R. Phlogene and P. Morand). ACS Symposium Series. American Chemical Society, Washington DC., USA. 387: 1-10.

Khattach, S.U. and Hameed, M. 1986. Control of pulse beetle, Callosobruchus chinensis L. by gamma radiation, irradiated as unmated adults. Bangladesh J. Zool., 14(2): 167-169. 
Mahmood, I., Saxena, S.K. and Zakiuddin, M. 1984. Effect of certain plant extracts on the mortality of Rotylenchulus reniformis and Meloidogyne incognita. Bangladesh J. Bot., 4(2): 154-157.

Mamun, M.S.A. 2011a. Tea pests and their integrated management in Bangladesh (Bangla). Krishi Tottho. Agro Bangla. Dhaka. pp. 1-4. (http:// www.agrobangla.com)

Mamun, M.S.A. 2011b. Development of tea science and tea industry in Bangladesh and advances of plant extracts in tea pest management. Int. J. Sustain. Agril. Tech., 7(5): 40-46.

Mamun, M.S.A. 2011c. Development of integrated pest management strategy for tea mosquito bug (Helopeltis theivora W.) in Bangladesh. J. Subtropical Agril. Res. \& Dev., 9(1) : 867873.

Mamun, M.S.A. 2011d. Indigenous plant extracts for the management of red flour beetle: An ecofriendly sustainable management of stored grain products". (ISBN: 978-3-84540160-7). LAP LAMBERT Academic Publishing $\mathrm{GmbH} \&$ Co. KG Dudweiler Landstr. 99, 66123 Saarbrücken, Germany. $112 \mathrm{p}$.

Mamun, M.S.A. and Ahmed, M. 2011. Studies on indigenous plant extract against major pests of tea. Unpublished research work of BTRI.

Mamun, M.S.A. and Iyengar, A.V.K. 2010. Integrated approaches to tea pest management in south India. Int. J. Sustain. Agril. Tech., 6(4): 27-33.

Mamun, M.S.A., Shahjahan, M. and Ahmad, M. 2008. Laboratory evaluation of some indigenous plant extracts as repellent against red flour beetle, Tribolium castaneum Herbst. Bangladesh j. entomol., 18(1): 91-99.

Mamun, M.S.A., Shahjahan, M. and Ahmad, M. 2009. Laboratory evaluation of some indigenous plant extracts as toxicants against red flour beetle, Tribolium castaneum Herbst. J . Bangladesh Agril. Univ., 7(1): 1-5.

Metcalf, R.L. 1975. Insecticides in pest management. pp. 235-273. In: R.L. Metcalf and W. Luckmann (eds.). Introduction to insect pest management. Willey-Inter. Sci. New York.

Mugisha-Kamatenesi, M., Deng, A.L., Ogendo, J.O., Omolo, E.O., Mihale, M.J., Otim, J.P.,
Buyungo and Bett, P.K. 2008. Indigenous knowledge of field insect pests and their management around lake Victoria basin in Uganda. African J. Environ. Sci. \& Tech., 2(8): 342-348.

Muraleedharan, N. 2005. Sustainable cultivation of tea. Planters' Chronicle, 101(5): 5-17.

Philip G.K. and Robert A.B. 1998. Florida Pest Control Association.

Pimental, D., Andow, D., Dyson-Hudson, D., Gallahan, D., J acobson, S., Irish, M., Croop, S., Moss, A., Schreiner, I., Shepard, M., Thompson, T. and Vinzant, B. 1980. Environmental and social cost of pesticides. A preliminary assessment. Oikos, 34: 125140.

Radhakrishnan, B. 2005. Indigenous preparations useful for pest and disease management. Planters' Chronicle, 101(4): 4-16.

Sana, D. L. 1989. Tea Science. Ashrafia Boi Ghar, 36, Bangla Bazar, Dhaka, Bangladesh. pp. 106-200.

Sarmah, M. and Bhola, R.K. 2008. Antifeedant and repellent effects of aqueous plant extracts of Azadirachta indica and Xanthium strumarium on tea mosquito bug, Helopeltis theivora Waterhouse. Two and a bud, 55: 36-40.

Sarmah, M., Rahman, A., Phukan, A.K. and Gurusubramanian, G. 2009. Effect of aqueous plant extracts on tea red spider mite, Oligonychus coffeae, Nietner (Tetranychidae: Acarina) and Stethorus gilvifrons Mulsant. African J. Biotech., 8(3): 417-423.

Schmutterer, H. and Singh, R.P. 1995. Lists of insects susceptible to neem products. In: The Neem Trees Sources of Unique Natural Products for Integrated Pest Management, Medicine, Industry and Other Purposes, Schmutterer, H. (Ed.), VCH Publishers, New York.

Sharaby, A. 1988. Evaluation of some Mytraceae plant leaves as protectants against the infestation by Sitophilus oryzae L. and Sitophilus granarius L. Insect Sci. Appl., 9: 465-468. 